\title{
HYPERPHOSPHATEMIA IN END-STAGE RENAL DISEASE: PREVALENCE AND PATIENTS CHARACTERISTICS OF MULTIETHNIC POPULATION OF UNITED ARAB EMIRATES
}

\author{
SYED ARMAN RABBANI ${ }^{*}$, SATHVIK B Sa , PADMA GM RA0, MARTIN THOMAS KURIAN ${ }^{b}$, BASSET EL ESSAWYb,c \\ aDepartment of Clinical Pharmacy and Pharmacology, RAK College of Pharmaceutical Sciences, RAK Medical and Health Sciences \\ University, Ras Al Khaimah, United Arab Emirates, bConsultant Nephrologist, Ibrahim bin Hamad Obaidallah Hospital, Ras al Khaimah, \\ United Arab Emirates, cAdjunct Professor, RAK Medical and Health Sciences University, Ras Al Khaimah, United Arab Emirates \\ Email: arman@rakmhsu.ac.ae
}

Received: 06 Sep 2017 Revised and Accepted: 02 Nov 2017

\begin{abstract}
Objective: Hyperphosphatemia is significantly associated with increased mortality among end-stage renal disease (ESRD) patients on hemodialysis. There is a paucity of data on hyperphosphatemia in ESRD patients of the multiethnic population of United Arab Emirates (UAE). The study aimed to investigate the prevalence and characteristics of hyperphosphatemia in ESRD patients of the multiethnic population of UAE undergoing
\end{abstract} maintenance hemodialysis.

Methods: Adults ESRD patients undergoing maintenance hemodialysis for more than six months at the study site were included. Demographic, clinical and biological data of the patients were collected. Patient characteristics were compared as per the serum phosphate level, between patients with or without hyperphosphatemia. Univariate and multivariate logistic regression analyses were carried out to identify the predictors of hyperphosphatemia.

Results: Hyperphosphatemia was present in $73.8 \%$ of the study population, while $31.3 \%$ presented with the high calcium-phosphate product. Univariate logistic analysis revealed that hyperphosphatemia was inversely correlated with age, haemoglobin, serum calcium, and hypertensive nephropathy as the cause of renal disease, and positively correlated with female gender, expatriate status, body mass index (BMI), a higher number of comorbidities, calcium-phosphate product and parathyroid hormone (PTH). Multivariate logistic regression model revealed that only age, BMI, haemoglobin and PTH independently correlated with hyperphosphatemia.

Conclusion: We report a high prevalence of hyperphosphatemia in multiethnic study population undergoing maintenance hemodialysis at a secondary care hospital in UAE. In this study population, only age, BMI, hemoglobin and PTH were identified as independent predictors of hyperphosphatemia.

Keywords: Hyperphosphatemia, ESRD, Hemodialysis, Serum phosphate

(C) 2017 The Authors. Published by Innovare Academic Sciences Pvt Ltd. This is an open access article under the CC BY license (http://creativecommons.org/licenses/by/4.0/) DOI: http://dx.doi.org/10.22159/ijpps.2017v9i12.22425

\section{INTRODUCTION}

Hyperphosphatemia in end-stage renal disease (ESRD) is a common and serious biochemical abnormality linked to vascular calcification, renal osteodystrophy and secondary hyperparathyroidism [1-4] The abnormality is significantly associated with increased mortality among ESRD patients on hemodialysis [5-7]. Studies have also shown a strong association of hyperphosphatemia with cardiovascular morbidity and mortality in ESRD patients [8-10] Consequently, adequate control of serum phosphate is a critical component in the clinical management of ESRD patients.

Management of hyperphosphatemia is challenging and a multi-faceted approach consisting of dialytic phosphate removal, dietary phosphate restrictions and use of phosphate binders [11]. A number of phosphate binders, each with its own potential advantages and disadvantages, are available for the management of hyperphosphatemia. Calciumbased phosphate binders are less expensive but their use is confined to the development of hypercalcemia. Non-calcium-based phosphate binders like sevelamer and lanthanum are expensive, and associated with gastrointestinal side effects [11-12]. More recently iron-based phosphate binders have also shown to be effective in controlling hyperphosphatemia [13].

In spite of recent advances in the therapeutic management of hyperphosphatemia, achievement and maintenance of guideline recommendations [11] for serum phosphate remain inadequate. Non-compliance with phosphate binders, non-adherence to dietary restrictions, inadequate dialysis, refractory disease states and financial limitations may account for inadequate control of hyperphosphatemia [3, 14-15].
This study was designed because there is a paucity of data on hyperphosphatemia in ESRD patients of the multiethnic population of United Arab Emirates (UAE). To our knowledge, no study in UAE has yet addressed hyperphosphatemia in ESRD patients on hemodialysis. The aim of this study was to investigate the prevalence and characteristics of hyperphosphatemia in ESRD patients of the multiethnic population of UAE undergoing maintenance hemodialysis.

\section{MATERIALS AND METHODS}

\section{Methods}

Study design and setting

This study was a prospective observational study involving ESRD patients undergoing maintenance hemodialysis at the dialysis unit of a secondary care hospital in RAK, UAE.

\section{Sample selection}

ESRD patients aged more than $18 \mathrm{y}$, either gender, undergoing maintenance hemodialysis for more than six months at the dialysis unit of the study site were included in the study. Patients with acute kidney injury, undergoing less than thrice weekly hemodialysis and who were on hemodialysis for less than six months were not included in the study.

\section{Data collection}

Demographic, clinical and biological data were collected from the electronic patient case records and documented in the data collection form designed for the study. Demographic and clinical data included age, 
sex, nationality, height, weight, body mass index (BMI), duration on hemodialysis, number of hemodialysis sessions/week, the cause of endstage renal disease, type of comorbidities, number of comorbidities and medications. Biological data included values of haemoglobin, serum creatinine, urea, calcium, phosphate, calcium-phosphate product, parathyroid hormone (PTH), alkaline phosphatase (ALP) and Kt/V. Serum phosphate was the parameter of interest. A serum phosphate level of $>1.45 \mathrm{mmol} / \mathrm{l}$ was considered hyperphosphatemia as per Kidney Disease Improving Global Outcomes (KDIGO) Clinical Practice Guideline for the Diagnosis, Evaluation, Prevention, and Treatment of Chronic Kidney Disease-Mineral and Bone Disorder (CKD-MBD) [11]. All data were collected and checked for completeness by the study investigators. The patients' adherence to dietary phosphate restrictions and phosphate binders was ascertained by the dialysis unit nursing staff.

\section{Data analysis}

Statistical analysis of the data was performed using the Statistical Package for the Social Sciences (SPSS) version 20.0. Continuous variables were expressed as the mean and standard deviation, and categorical variables were expressed as percentages. Serum phosphate was the only quantitative parameter analyzed as a two-category variable: normal or high (threshold $1.45 \mathrm{mmol} / \mathrm{l}$ ). Patient characteristics were compared as per the serum phosphate level, between patients with normal or high serum phosphate levels using the Pearson $\chi 2$ test for categorical variables and ANOVA for continuous variables. Univariate and multivariate logistic regression analyses were carried out to identify the predictors of hyperphosphatemia. Variables showing the tendency of association with hyperphosphatemia $(\mathrm{P}<0.25)$ in univariate analysis were considered for multivariate logistic regression analysis to identify independent predictors of hyperphosphatemia. $\mathrm{P}<0.05$ was considered statistically significant.

\section{Ethics approval}

The study was approved by Ras Al Khaimah (RAK) Medical and Health Sciences University Research and Ethics Committee (Number: 4-2015-F-P), and RAK Research and Ethics Committee, UAE (Number: Sep-2015-1). No formal informed consent was required as it was an observational study.

\section{RESULTS}

Out of the 100 patients undergoing maintenance hemodialysis at the study site, 20 patients were not included in the study as they met the exclusion criteria. Therefore 80 patients were considered for data analysis. The mean age of the patients was $61.1 \pm 9.4$ y and $57.5 \%$ were females. The mean BMI of the study population was $27.5 \pm 2.1$. Thirty-five $(43.8 \%)$ patients were locals (Emiratis) whereas 45 $(56.2 \%)$ were expatriates.

Among the patients studied, 59 (73.8\%) presented with hyperphosphatemia and 21 (31.3\%) presented with the high calciumphosphate product (defined by the mean calcium-phosphate product $>4.4 \mathrm{mmol}^{2} / \mathrm{l}^{2}$. The study population had mean serum phosphate level of $1.73 \pm 0.45 \mathrm{mmol} / \mathrm{l}$ and mean calcium-phosphate product level of $3.7 \pm 0.9 \mathrm{mmol}^{2} / \mathrm{l}^{2}$. The mean $\mathrm{Kt} / \mathrm{V}$ value of the study population was $1.28 \pm 0.26$. Overall, 72 patients $(90 \%)$ were receiving phosphate binders. Out of these 72 patients, 17 (21.3\%) were receiving sevelamer alone, $14(17.5 \%)$ were receiving calcium carbonate alone and $41(51.2 \%)$ were receiving sevelamer as well as calcium carbonate.

Table 1 shows the descriptive data of the study population stratified by the level of serum phosphate.

Table 1: Characteristics of ESRD patients with and without hyperphosphatemia

\begin{tabular}{|c|c|c|c|c|c|}
\hline \multirow[t]{2}{*}{ Variable } & \multirow[t]{2}{*}{$\mathbf{N}$} & \multirow[t]{2}{*}{ All subjects } & \multicolumn{2}{|c|}{ Serum phosphate (mmol/l) } & \multirow[t]{2}{*}{ P-value } \\
\hline & & & $\leq 1.45(n=21)$ & $>1.45(n=59)$ & \\
\hline Age, years $(\mathrm{m} \pm \mathrm{SD})$ & 80 & $61.1 \pm 9.4$ & $64.6 \pm 10.9$ & $59.8 \pm 8.6$ & 0.046 \\
\hline \multicolumn{6}{|l|}{ Gender $(\%)$} \\
\hline Female & 80 & 57.5 & 38.1 & 64.4 & 0.043 \\
\hline Male & & 42.5 & 61.9 & 35.6 & \\
\hline Nationality (\%) & 80 & & & & 0.021 \\
\hline Emirati & & 43.8 & 66.7 & 35.6 & \\
\hline Expatriate & & 56.2 & 33.3 & 64.4 & \\
\hline Hemodialysis duration (\%) & 80 & & & & 0.059 \\
\hline$\leq 2$ years & & 68.8 & 85.7 & 62.7 & \\
\hline$>2$ years & & 31.2 & 14.3 & 37.3 & \\
\hline Body mass index, $\mathrm{kg} / \mathrm{m}^{2}(\mathrm{~m} \pm \mathrm{SD})$ & 80 & $27.5 \pm 2.1$ & $26.2 \pm 0.8$ & $27.9 \pm 2.2$ & $<0.001$ \\
\hline Cause of renal disease $(\%)$ & 80 & & & & 0.016 \\
\hline Hypertensive Nephropathy & & 33.8 & 57.2 & 25.4 & \\
\hline Diabetic Nephropathy & & 25.0 & 9.5 & 30.5 & \\
\hline Hypertensive+Diabetic Nephropathy & & 28.7 & 14.3 & 33.9 & \\
\hline Others & & 12.5 & 19.0 & 10.2 & \\
\hline Number of comorbidities (\%) & 80 & & & & 0.011 \\
\hline One to two comorbidities & & 51.2 & 76.2 & 42.4 & \\
\hline More than two comorbidities & & 48.8 & 23.8 & 57.6 & \\
\hline \multicolumn{6}{|l|}{ Laboratory variables $(\mathrm{m} \pm \mathrm{SD})$} \\
\hline Hemoglobin, g/dl & 80 & $10.93 \pm 1.1$ & $11.6 \pm 1.9$ & $10.7 \pm 1.1$ & 0.001 \\
\hline Serum creatinine, mmol/l & 80 & $426.8 \pm 157.7$ & $409.9 \pm 160.3$ & $432.8 \pm 157.8$ & 0.571 \\
\hline Urea, mmol/l & 80 & $11.3 \pm 5.6$ & $10.5 \pm 6.8$ & $11.6 \pm 5.1$ & 0.434 \\
\hline Serum calcium, mmol/l & 80 & $2.1 \pm 0.2$ & $2.2 \pm 0.2$ & $2.1 \pm 0.2$ & 0.006 \\
\hline Calcium x Phosphate, $\mathrm{mmol}^{2} / \mathrm{l}^{2}$ & 80 & $3.7 \pm 0.9$ & $2.8 \pm 0.8$ & $3.9 \pm 0.8$ & $<0.001$ \\
\hline Parathyroid hormone, pmol/l & 80 & $64.9 \pm 58.6$ & $39.7 \pm 13.9$ & $73.9 \pm 65.5$ & 0.020 \\
\hline Alkaline phosphatase, IU/l & 80 & $134.1 \pm 137.6$ & $150.2 \pm 157.5$ & $128.4 \pm 130.9$ & 0.537 \\
\hline \multicolumn{6}{|l|}{ Medications (\%) } \\
\hline ACEI & 80 & 17.5 & 23.8 & 15.3 & 0.283 \\
\hline $\mathrm{ARB}$ & 80 & 33.8 & 33.3 & 33.9 & 0.593 \\
\hline CCB & 80 & 82.5 & 81.0 & 83.1 & 0.532 \\
\hline Diuretics & 80 & 38.8 & 19.0 & 45.8 & 0.026 \\
\hline Beta Blockers & 80 & 38.8 & 42.9 & 37.3 & 0.422 \\
\hline Hypoglycemics & 80 & 62.5 & 52.4 & 66.1 & 0.196 \\
\hline Phosphate binders & 80 & 90.0 & 61.9 & 100 & $<0.001$ \\
\hline ESA & 80 & 86.3 & 71.4 & 91.5 & 0.032 \\
\hline Iron supplements & 80 & 97.5 & 95.2 & 98.3 & 0.459 \\
\hline Hypolipedimics & 80 & 77.5 & 71.4 & 79.7 & 0.312 \\
\hline
\end{tabular}

$A C E I$ angiotensin-converting-enzyme inhibitors, $A R B$ angiotensin receptor blockers, $C C B$ calcium channel blockers, ESA erythropoiesis-stimulating agent. Statistically significant values are in bold 
Patients with hyperphosphatemia were younger $(\mathrm{p}=0.046)$, more often females $(\mathrm{p}=0.043)$ and expatriates $(\mathrm{p}=0.021)$, had a higher BMI $(\mathrm{p}<0.001)$ and presented with a higher number of comorbidities $(p=0.011)$ as compared to those with normal serum phosphate levels. They were less likely to have hypertensive nephropathy and more likely to have diabetic nephropathy as the cause of their renal disease. Patients with hyperphosphatemia had lower serum calcium $(p=0.006)$ and hemoglobin ( $p=0.001)$, and higher calcium-phosphate product $(\mathrm{p}<0.001)$ and PTH $(\mathrm{p}=0.020)$ as compared to those without hyperphosphatemia.
Univariate logistic analysis revealed that hyperphosphatemia was inversely correlated with age (OR $0.93,95 \%$ CI $0.87-1.00$ ), hemoglobin (OR 0.44, 95\% CI 0.26-0.77), serum calcium (OR 0.03, 95\% CI 0.00-0.45) and hypertensive nephropathy as cause of renal disease (OR 0.15, 95\% CI 0.04-0.50). Hyperphosphatemia was positively correlated with female gender (OR 2.94, 95\% CI 1.058.23), expatriate status (OR 3.61, 95\% CI 1.26-10.36), BMI (OR 1.77, 95\% CI 1.22-2.56), higher number of comorbidities (OR 3.40, 95\% CI 1.15-9.99), calcium-phosphate product (OR $12.36,95 \%$ CI 3.79 40.32) and PTH (OR 1.04, 95\% CI 1.02-1.07) (table 2).

Table 2: Univariate logistic regression analysis demonstrating relationship of hyperphosphatemia with other variables in ESRD patients

\begin{tabular}{|c|c|c|c|}
\hline Variable (reference) & Odds Ratio & $95 \%$ CI & P-value \\
\hline Age, years & 0.93 & $0.87-1.00$ & 0.049 \\
\hline \multicolumn{4}{|l|}{ Gender (Male) } \\
\hline Female & 2.94 & $1.05-8.23$ & 0.040 \\
\hline \multicolumn{4}{|l|}{ Nationality (Emirati) } \\
\hline Expatriate & 3.61 & $1.26-10.36$ & 0.017 \\
\hline Body mass index, k/gm & 1.77 & $1.22-2.56$ & 0.002 \\
\hline \multicolumn{4}{|c|}{ Number of comorbidities (one to two comorbidities) } \\
\hline More than two comorbidities & 3.40 & $1.15-9.99$ & 0.026 \\
\hline \multicolumn{4}{|c|}{ Cause of renal disease (Diabetic Nephropathy) } \\
\hline Hypertensive Nephropathy & 0.15 & $0.04-0.50$ & 0.002 \\
\hline Hemoglobin, g/dl & 0.44 & $0.26-0.77$ & 0.004 \\
\hline Serum creatinine, $\mathrm{mmol} / \mathrm{l}$ & 1.00 & $0.99-1.00$ & 0.566 \\
\hline Urea, mmol/l & 1.04 & $0.94-1.14$ & 0.431 \\
\hline Serum calcium, mmol/l & 0.03 & $0.00-0.45$ & 0.011 \\
\hline Calcium x Phosphate, $\mathrm{mmol}^{2} / \mathrm{l}^{2}$ & 12.36 & $3.79-40.32$ & $<0.001$ \\
\hline Parathyroid hormone, pmol/l & 1.04 & $1.02-1.07$ & 0.001 \\
\hline Alkaline phosphatase, IU/l & 0.99 & $0.99-1.00$ & 0.538 \\
\hline \multicolumn{4}{|l|}{ Phosphate binder (Sevelamer) } \\
\hline Calcium carbonate & 0.53 & $0.09-2.94$ & 0.472 \\
\hline Sevelamer+Calcium carbonate & 1.25 & $0.27-5.70$ & 0.773 \\
\hline
\end{tabular}

CI confidence interval. Statistically significant values are in bold,

Multivariate logistic regression model revealed that age (OR 0.84 , 95\% CI 0.72-0.97), BMI (OR 2.15, 95\% CI 1.25-3.68), hemoglobin
(OR 0.24, 95\% CI 0.06-0.97) and PTH (OR 1.09, 95\% CI 1.01-1.17) independently correlated with hyperphosphatemia (table 3).

Table 3: Multivariate logistic regression analysis of selected variables associated with hyperphosphatemia in ESRD patients

\begin{tabular}{|c|c|c|c|}
\hline Variable (reference) & Odds ratio & 95\% CI & P-value \\
\hline Age, years & 0.84 & $0.72-0.97$ & 0.023 \\
\hline \multicolumn{4}{|l|}{ Gender (Male) } \\
\hline Female & 3.52 & $0.30-41.41$ & 0.316 \\
\hline \multicolumn{4}{|l|}{ Nationality (Emirati) } \\
\hline Expatriate & 3.75 & $0.42-33.21$ & 0.234 \\
\hline Body mass index, kgm & 2.15 & $1.25-3.68$ & 0.005 \\
\hline \multicolumn{4}{|c|}{ Number of comorbidities (one to two comorbidities) } \\
\hline More than two comorbidities & 1.65 & $0.08-33.68$ & 0.744 \\
\hline \multicolumn{4}{|c|}{ Cause of renal disease (Diabetic Nephropathy) } \\
\hline Hypertensive Nephropathy & 0.31 & $0.02-4.97$ & 0.408 \\
\hline Hemoglobin, g/dl & 0.24 & $0.06-0.97$ & 0.045 \\
\hline Serum calcium, mmol/l & 0.046 & $0.00-7.98$ & 0.242 \\
\hline Parathyroid hormone, pmol/l & 1.09 & $1.01-1.17$ & 0.030 \\
\hline
\end{tabular}

CI confidence interval. Statistically significant values are in bold

\section{DISCUSSION}

Hyperphosphatemia is significantly associated with increased cardiovascular morbidity and all-cause mortality among ESRD patients on maintenance hemodialysis. Hyperphosphatemia was present in $73.8 \%$ of our patients. The reported prevalence of hyperphosphatemia in dialysis patients based on different studies is between $50 \%$ and $70 \%$ [16-19]. Our results are in line with these published studies, although there is a slightly higher prevalence of hyperphosphatemia in our study population which can be attributed to the variability in the age, gender, BMI and ethnic backgrounds between our patients and those previously studied. In addition, our study also showed that $31.3 \%$ of the patients presented with the high calcium-phosphate product. This finding is similar to previously published studies $[16-17,19]$. Studies have demonstrated that both hyperphosphatemia and high calcium-phosphate product are implicated in cardiovascular events and mortality among dialysis patients $[5-7,20]$.

Guidelines recommend adequate control of serum phosphate with phosphate-restricted diet, oral phosphate binders and dialytic phosphate removal in patients with ESRD on dialysis [11]. There are no definite recommendations for the use of a specific phosphate binder for all the patients because of inconclusive data on their 
comparative efficacy. Appropriate selection of the phosphate binder should be done taking into account CKD stage, the presence of different components of CKD-MBD, concomitant drug therapies and safety profile of the phosphate binder [11]. In our study, more than half of the patients $(51.2 \%)$ were receiving both sevelamer and calcium carbonate, $21.3 \%$ and $17.5 \%$ were receiving sevelamer alone and calcium carbonate alone respectively. Calcium-based phosphate binders are associated with hypercalcemia which can lead to extra-skeletal calcification and PTH suppression. In relation to biochemical endpoints several studies [21-22] reported that both sevelamer and calcium-based salts were equally effective as phosphate binders.

In our study hyperphosphatemia was inversely correlated with age, hypertensive nephropathy, haemoglobin and serum calcium, and positively correlated with female gender, expatriate status, BMI, a higher number of comorbidities, calcium-phosphate product and PTH by univariate analysis. However, multivariate analysis indicated that only age, BMI, haemoglobin and PTH independently correlated with hyperphosphatemia.

The correlation between hyperphosphatemia and lower age has been reported by many studies conducted in chronic kidney disease as well as dialysis population [6,20,23-24]. This can be attributed to the reduced dietary phosphate intake and changes in renal phosphate handling with age [25].

Several studies have reported a correlation between hyperphosphatemia and female gender [23, 26-27], a similar finding was observed in our study as well. The reasons for this association are not clear and may be ascribed to the estrogen-mediated regulation of renal phosphate reabsorption $[25,28]$.

Hyperphosphatemia and its association with higher BMI have been described in dialysis population $[5,23,29]$. The reason can be attributed to the fact that the major determinants of both the BMI and serum phosphate are the dietary habits and nutritional status.

The population of UAE is multi-ethnic comprising of Emiratis and expatriates from different countries like India, Pakistan, Bangladesh, Sri Lanka, Egypt, Iraq, Syria, Iran, etc. The correlation of hyperphosphatemia and expatriates may be attributed to external factors like their dietary habits consisting of high consumption of protein-rich diet and processed foods with high phosphate contents. Further studies are warranted to elucidate precise factors for this correlation.

The inverse association of hyperphosphatemia with hypertensive nephropathy has been reported by a previous study [23]. The mechanisms underlying this association are not known. Hyperphosphatemia and its positive association with a higher number of comorbidities may be explained by the derangements of mineral metabolism in the presence of multiple comorbidities.

Recent studies have reported the association of hyperphosphatemia with low haemoglobin in individuals without kidney disease [30, 27], in early CKD [27], in ESRD patients [31] and kidney transplant recipients [32]. Many mechanisms have been put forward to explain this association in CKD and ESRD patients. This relationship may be mediated by inhibition of erythropoiesis both by elevated PTH [33] and uremic toxins polyamines [32], elevated PTH induced breakdown of RBCs [34] and bone marrow fibrosis [34-35].

As the renal function worsens, mineral metabolism progressive deteriorates; hypocalcemia develops as a result of fall in activated vitamin D levels increasing PTH, leading to secondary hyperparathyroidism [36-37]. This explains the association of hyperphosphatemia with low serum calcium and high PTH level.

The main limitations of our study were that it was an observational, single-centre study with a small sample size, which may not be the complete representation of the multiethnic population of UAE.

\section{CONCLUSION}

In conclusion, we report a high prevalence of hyperphosphatemia in multiethnic study population undergoing maintenance hemodialysis at a secondary care hospital in UAE. We found out that in our study population hyperphosphatemia was associated with lower age, female gender, expatriate status, higher BMI, lower haemoglobin and serum calcium, higher PTH and a higher number of comorbidities. Furthermore, our results revealed that only age, hemoglobin, BMI and PTH were the independent predictors of hyperphosphatemia.

\section{ACKNOWLEDGEMENT}

The authors would like to thank the administration of Ibrahim Bin Hamad Obaidallah Hospital, RAK, UAE. The authors also thank Dr. S Gurumadhva Rao, Vice Chancellor; Dr. BG Nagavi, Dean; RAK Medical and Health Sciences University for their support and encouragement.

\section{AUTHORS CONTRIBUTION}

Syed Arman Rabbani was involved in conceptualization, design and conduct of the study, literature search, data acquisition, statistical analysis and manuscript preparation. Sathvik BS was involved in the conceptualization of the study, statistical analysis, manuscript editing and review. Padma GM Rao, Martin Thomas Kurian, Basset El Essawy were involved conceptualization of the study, manuscript editing and review.

\section{CONFLICT OF INTERESTS}

Declared none

\section{REFERENCES}

1. Giachelli CM. The emerging role of phosphate in vascular calcification. Kidney Int 2009;75:890-7.

2. Nishizawa Y, Jono S, Ishimura E, Shioi A. Hyperphosphatemia and vascular calcification in end-stage renal disease. J Ren Nutr 2005;15:178-82.

3. Coladonato JA. Control of hyperphosphatemia among patients with ESRD. J Am Soc Nephrol 2005;16 Suppl 2:S107-14.

4. Shaman AM, Kowalski SR. Hyperphosphatemia management in patients with chronic kidney disease. Saudi Pharm J 2016;24:494-505.

5. Block GA, Klassen PS, Lazarus JM, Ofsthun N, Lowrie EG, Chertow GM. Mineral metabolism, mortality, and morbidity in maintenance hemodialysis. J Am Soc Nephrol 2004;15:2208-18.

6. Naves Díaz M, Passlick Deetjen J, Guinsburg A, Marelli C, Fernández Martín JL, Rodríguez-Puyol D, et al. Calcium, phosphorus, PTH and death rates in a large sample of dialysis patients from latin America. The CORES Study. Nephrol Dial Transplant 2011;26:1938-47.

7. Tentori F, Blayney MJ, Albert JM, Gillespie BW, Kerr PG, Bommer J, et al. Mortality risk for dialysis patients with different levels of serum calcium, phosphorus, and PTH: the dialysis outcomes and practice patterns study (DOPPS). Am J Kidney Dis 2008;52:519-30.

8. Ganesh SK, Stack AG, Levin NW, Hulbert-Shearon T, Port FK. Association of elevated serum PO, Ca x PO product, and parathyroid hormone with cardiac mortality risk in chronic hemodialysis patients. J Am Soc Nephrol 2001;12:2131-8.

9. Dhingra R, Gona P, Benjamin EJ, Wang TJ, Aragam J, D’Agostino RBSr, et al. Relations of serum phosphorus levels to echocardiographic left ventricular mass and incidence of heart failure in the community. Eur J Heart Fail 2010;12:812-8.

10. McGovern AP, de Lusignan S, van Vlymen J, Liyanage H, Tomson $\mathrm{CR}$, Gallagher $\mathrm{H}$, et al. Serum phosphate as a risk factor for cardiovascular events in people with and without chronic kidney disease: a large community-based cohort study. PLoS One 2013;8:e74996.

11. Kidney Disease: Improving Global Outcomes (KDIGO) CKDMBD Work Group. KDIGO clinical practice guideline for the diagnosis, evaluation, prevention, and treatment of Chronic Kidney Disease-Mineral and Bone Disorder (CKD-MBD). Kidney Int Suppl; 2009. p. S1-130.

12. Floege J. Phosphate binders in chronic kidney disease: a systematic review of recent data. J Nephrol 2016;29:329-40.

13. Lee CT, Wu IW, Chiang SS, Peng YS, Shu KH, Wu MJ, et al. Effect of oral ferric citrate on serum phosphorus in hemodialysis patients: multicenter, randomized, double-blind, placebocontrolled study. J Nephrol 2015;28:105-13. 
14. Spasovski G. Advances in pharmacotherapy for hyperphosphatemia in renal disease. Expert Opin Pharmacother 2015;16:2589-99.

15. Sherman RA. Hyperphosphatemia in dialysis patients: beyond nonadherence to diet and binders. Am J Kidney Dis 2016;67:182-6.

16. Afifi A, El-Sayed H, El-Setouhi M, Ahmed H, Khalifa N. Hyperphosphatemia among end-stage renal disease patients in developing countries: a forgotten issue? Hemodial Int 2005; 9:409-15.

17. Young EW, Albert JM, Satayathum S, Goodkin DA, Pisoni RL, Akiba T, et al. Predictors and consequences of altered mineral metabolism: the dialysis outcomes and practice patterns study. Kidney Int 2005;67:1179-87.

18. Ramos AM, Albalate M, Vázquez S, Caramelo C, Egido J, Ortiz A. Hyperphosphatemia and hyperparathyroidism in incident chronic kidney disease patients. Kidney Int Suppl 2008;111:S88-93.

19. Block GA, Port FK. Re-evaluation of risks associated with hyperphosphatemia and hyperparathyroidism in dialysis patients: recommendations for a change in management. Am J Kidney Dis 2000;35:1226-37.

20. Block GA, Hulbert-Shearon TE, Levin NW, Port FK. Association of serum phosphorus and calcium $\mathrm{x}$ phosphate product with mortality risk in chronic hemodialysis patients: a national study. Am J Kidney Dis 1998;31:607-17.

21. Ferreira A, Frazao JM, Monier-Faugere MC, Gil C, Galvao J, Oliveira C, et al. Sevelamer study group. Effects of sevelamer hydrochloride and calcium carbonate on renal osteodystrophy in hemodialysis patients. J Am Soc Nephrol 2008;19:405-12.

22. St Peter WL, Liu J, Weinhandl E, Fan Q. A comparison of sevelamer and calcium-based phosphate binders on mortality, hospitalization, and morbidity in hemodialysis: a secondary analysis of the dialysis clinical outcomes revisited (DCOR) randomized trial using claims data. Am J Kidney Dis 2008;51:445-54.

23. Laurain E, Thilly N, Boini S, Kessler M, Briançon S, Frimat L. Hyperphosphatemia in chronic kidney disease: patient characteristics and dialysis mortality during the first year of dialysis. J Nephrol Ther 2012;S3:009.

24. Bellasi $\mathrm{A}$, Mandreoli $\mathrm{M}$, Baldrati $\mathrm{L}$, Corradini $\mathrm{M}$, Di Nicolò $\mathrm{P}$ Malmusi G, et al. Chronic kidney disease progression and outcome according to serum phosphorus in mild-to-moderate kidney dysfunction. Clin J Am Soc Nephrol 2011;6:883-91.

25. Cirillo M, Ciacci C, De Santo NG. Age, renal tubular phosphate reabsorption, and serum phosphate levels in adults. N Engl J Med 2008;359:864-6.
26. Onufrak SJ, Bellasi A, Cardarelli F, Vaccarino V, Muntner P, Shaw LJ, et al. Investigation of gender heterogeneity in the associations of serum phosphorus with incident coronary artery disease and all-cause mortality. Am J Epidemiol 2009;169:67-77.

27. Wojcicki JM. Hyperphosphatemia is associated with anemia in adults without chronic kidney disease: results from the National Health and Nutrition Examination Survey (NHANES): 2005-2010. BMC Nephrol 2013;14:178.

28. Uemura H, Irahara M, Yoneda N, Yasui T, Genjida K, Miyamoto $\mathrm{KI}$, et al. Close correlation between estrogen treatment and renal phosphate reabsorption capacity. J Clin Endocrinol Metab 2000;85:1215-9.

29. Wang AY, Woo J, Sea MM, Law MC, Lui SF, Li PK. Hyperphosphatemia in Chinese peritoneal dialysis patients with and without residual kidney function: what are the implications? Am J Kidney Dis 2004;43:712-20.

30. Tran L, Batech M, Rhee CM, Streja E, Kalantar-Zadeh K, Jacobsen SJ, et al. Serum phosphorus and association with anemia among a large diverse population with and without chronic kidney disease. Nephrol Dial Transplant 2016;31:636-45.

31. Grzegorzewska AE, Młot-Michalska M. Bone mineral density, its predictors, and outcomes in peritoneal dialysis patients. Adv Peritoneal Dial 2011;27:140-5.

32. Kovesdy CP, Mucsi I, Czira ME, Rudas A, Ujszaszi A, Rosivall L, et al. Association of serum phosphorus level with anemia in kidney transplant recipients. Transplantation 2011;91:875-82.

33. Meytes D, Bogin E, Ma A, Dukes PP, Massry SG. Effect of parathyroid hormone on erythropoiesis. J Clin Invest 1981;67:1263-9.

34. Bogin E, Massry SG, Levi J, Djaldeti M, Bristol G, Smith J. Effect of parathyroid hormone on osmotic fragility of human erythrocytes. J Clin Invest 1982;69:1017-25.

35. Rao DS, Shih MS, Mohini R. Effect of serum parathyroid hormone and bone marrow fibrosis on the response to erythropoietin in uremia. N Engl J Med 1993;328:171-5.

36. Hruska KA, Mathew S, Lund R, Qiu P, Pratt R. Hyperphosphatemia of chronic kidney disease. Kidney Int 2008;74:148-57.

37. Kestenbaum B, Belozeroff V. Mineral metabolism disturbances in patients with chronic kidney disease. Eur J Clin Invest 2007;37:607-22. 